\title{
Transition of the Journal of Intercollegiate Sport
}

\author{
Laura J. Burton, Editor-in-Chief \\ Jon Welty-Peachey, Associate Editor
}

With the first issues of 2019 we are pleased to announce that the Journal of Intercollegiate Sport will now be published as an open access journal supported by the University of Kansas online journal platform Journals@KU. The transition to our new platform follows ten successful years of publication and support through Human Kinetics Journals.

The rigor and quality of the journal will remain, as we consider the Journal of Intercollegiate Sport a premiere outlet for scholarly work in the context of intercollegiate sport. With the new open access platform the work published in the journal will now be widely available to download and share (with no associated fees). We believe this will continue to enhance the reputation of the journal, as the important scholarship that has been and will continue to be published in the journal will now be easily accessible to readers including our academic and professional communities. As such, we encourage all authors to widely share their work on available platforms.

The transition to our new platform would not have been possible without the support of Casey Butcha, Kathleen Burgener and many others at Human Kinetics. Further, we are grateful to Jordan Bass, faculty member at the University of Kansas and editor of the Journal of Amateur Sport. Jordan was instrumental in connecting us to Marianne Reed, Pamela LeRow and the staff in the Journals@KU program at the University of Kansas. We are appreciative of their insights, patience and professionalism as we learn a new publishing platform.

Beginning in August of 2019 Jon Welty Peachey will assume the role of Editor-in-Chief of the Journal of Intercollegiate Sport. Finally, the journal could not exist without the time, dedication and knowledge graciously provided by members of the Editorial Board. Thank you for your contributions to the continued success of the journal. 